\title{
Plano de Ação Palmas Sustentável 2015: processo de planejamento e justiça social
}

\author{
Sarah Afonso Rodovalho \\ Universidade Federal do Tocantins (UFT) \\ Alex Pizzio \\ Universidade Federal do Tocantins (UFT) \\ Monica Aparecida da Rocha Silva \\ Universidade Federal do Tocantins (UFT)
}

Recebido: 12/03/2019 Versão revisada (entregue): 24/05/2019 Aprovado: 06/06/2019

\begin{abstract}
Resumo
Este artigo tem como objetivo analisar a construção do diagnóstico do Plano de Ação Palmas Sustentável 2015. Metodologicamente, realizou-se pesquisa bibliográfica, documental e análise do conteúdo do documento final elaborado pelo Instituto Pólis, pelo Banco Interamericano de Desenvolvimento e pela Prefeitura Municipal de Palmas. O trabalho buscou compreender as características da Iniciativa Cidades Emergentes e Sustentáveis (ICES), a finalidade da inclusão de Palmas na ICES e a metodologia de trabalho; ainda examinou, no decorrer do documento, os dados apresentados sobre a realidade urbana de Palmas e as prioridades de ação. Os pressupostos teóricos acerca do entendimento de desenvolvimento em sua abordagem socioespacial urbana e da justiça social serviram como instrumentos para as análises realizadas. Pode-se observar que a visão de desenvolvimento do Plano de Ação Palmas Sustentável 2015 não considera a justiça social em suas três dimensões como ponto de partida para seu processo de planejamento.
\end{abstract}

Palavras-chave | Banco Interamericano de Desenvolvimento; desenvolvimento; Iniciativa Cidades Emergentes e Sustentáveis; justiça social; Plano de Ação Palmas Sustentável 2015.

Código JEL | O18 O21 R12

\section{Sustainable Palmas Action Plan 2015: planning process and social justice}

\begin{abstract}
This article aimed to analyze the diagnosis creation of the Sustainable Palmas Action Plan 2015. Methodologically, a bibliographical and documentary research was carried out along with an analysis on the final document, prepared by the Polis Institute, by the Inter-American Development Bank (IDB) and by the Palmas Town Hall. It sought to understand, in a specific way, the characteristics of the Emerging and Sustainable Cities Initiative (ICES), the purpose behind de inclusion of the city of Palmas in ICES and the methodology of the work. It also analyzes, in the course of the document, data presented about Palmas' urban reality and the evaluation of the action priorities. The theoretical assumptions about development in its urban
\end{abstract}


socio-spatial approach and on social justice served as tools for the performed analyses. Accordingly, it was possible to observe that the development vision by the Sustainable Palmas Action Plan does not consider social justice in its three dimensions as a starting point for its planning process.

Keywords | development; Emerging and Sustainable Cities Initiative; Inter-American Development Bank; social justice; Sustainable Palmas Action Plan 2015.

JEL-Code | O18 O21 R12

\section{Plan de Acción Palmas Sostenible 2015: proceso de planificación y justicia social}

\section{Resumen}

Este artículo tiene como objetivo analizar la construcción del diagnóstico del Plan de Acción Palmas Sostenible (PALMAS, 2015). Metodológicamente, se realizó una investigación bibliográfica y documental y análisis del contenido del documento final elaborado por el Instituto Pólis, por el Banco Interamericano de Desarrollo (BID) y por la Alcaldía de Palmas. El trabajo trató de entender las características de la Iniciativa Ciudades Emergentes y Sostenibles (ICES), el propósito de la inclusión de Palmas en la ICES y la metodología de trabajo; aun discute, al largo del documento, los datos presentados sobre la realidad urbana en Palmas y las prioridades de acción. Los supuestos teóricos sobre desarrollo en su enfoque socioespacial urbano y sobre justicia social sirvieron como instrumentos para los análisis realizados. Fue posible observar que la visión del desarrollo del Plan de Acción Palmas Sostenible no considera la justicia social en sus tres dimensiones como punto de partida para su proceso de planificación.

Palabras-clave | Banco Interamericano de Desarrollo; desarrollo; Iniciativa Ciudades Emergentes y Sostenibles; justicia social; Plan de Acción Palmas Sostenible 2015.

Código JEL | O18 O21 R12

\section{Introdução}

No campo do desenvolvimento urbano e regional, as atividades de planejamento e gestão do território, em suas escalas variadas, pretendem efetivar de fato o desenvolvimento (SOUZA, 2010). Contudo, a compreensão do sentido e a aplicação deste conceito e sua relação com o conceito de justiça social ainda são deficitários na prática de planejamento e gestão urbanos dos municípios brasileiros. Este artigo tem como objetivo analisar a construção do diagnóstico do Plano de Ação Palmas Sustentável publicado em 2015 na cidade de Palmas, capital do estado do Tocantins. 
Os pressupostos teóricos sobre desenvolvimento em sua abordagem socioespacial urbana e sobre justiça social serviram como instrumentos para as análises realizadas. Nesta análise, buscou-se compreender, de maneira específica, as características da Iniciativa Cidades Emergentes e Sustentáveis (ICES). A finalidade da inclusão da cidade de Palmas na ICES e a metodologia de elaboração do diagnóstico. Também se discute os dados apresentados sobre a realidade urbana em Palmas e a avaliação das prioridades de ação apresentadas no decorrer do documento estudado intitulado Plano de Ação Palmas Sustentável (PALMAS, 2015).

A ICES, do Banco Interamericano de Desenvolvimento (BID) (PALMAS, 2015), colocou em prática um programa de assistência técnica voltado aos governos das cidades médias da América Latina e Caribe (ALC). O BID tem demonstrado interesse em desempenhar um papel central em diversas cidades no Brasil e em toda a ALC no sentido de apoiar um crescimento equilibrado e que não seja um limitante ao desenvolvimento destas cidades. O Plano de Ação Palmas Sustentável é um dos elaborados dentro desse programa de assistência técnica.

O fortalecimento de trabalhos sobre desenvolvimento urbano traz consigo a necessidade de caracterização e contextualização das cidades, tendo em vista que elas são os locais de maiores investimentos de capital e conflitos sociais (CORRÊEA, 1995) e os lugares por excelência para a reprodução do capital e da força de trabalho (MARICATO, 2015).

Nesta perspectiva, o artigo inicia-se com pesquisa bibliográfica dos conceitos de desenvolvimento e justiça social que serviram como base para a análise realizada. Utiliza-se, nessa revisão, autores como Boisier (1996, 1999), Evans (2003) e Souza (2010) para o conceito de desenvolvimento, e Fraser (2008) e Pizzio (2016) para as discussões sobre a justiça social.

Metodologicamente, realizou-se também pesquisa documental e análise do conteúdo do documento final elaborado pelo Instituto Pólis, consultoria responsável pelo Plano de Ação, pelo BID e pela prefeitura de Palmas. O foco da análise aqui realizada se deu sobre a elaboração do diagnóstico do Plano, consubstanciado como a etapa inicial do processo. Cabe destacar que as diretrizes e ações propriamente ditas do Plano de Ação não foram objetos das análises deste artigo. A abordagem se dedicou aos questionamentos iniciais em relação ao consenso político, ao pacto social coletivo e ao processo de concepção e elaboração do diagnóstico do projeto de desenvolvimento urbano para a cidade.

Quanto à categoria conceitual de desenvolvimento, buscou-se interpretar seu significado no corpo do texto e se o caráter de desenvolvimento defendido pelo Plano de Ação se articulava com a ideia de justiça social. Ainda, se a metodologia utilizada para diagnosticar a realidade urbana e para definir as prioridades de ação respondia à busca da justiça social em sua dimensão política da representação por meio da ideia de paridade na participação defendida por Fraser (2008). 
Cabe destaque que as menções do termo desenvolvimento que foram encontradas pertinentes aos nomes do Banco Interamericano de Desenvolvimento, do Índice de Desenvolvimento Humano e do Atlas de Desenvolvimento Humano do Brasil foram desconsideradas para a análise, visto que representam um nome próprio de instituições que não são essencialmente objeto de análise deste artigo.

No que se refere aos resultados e discussão, são apresentados dois itens. O primeiro deles trata da ICES, seus objetivos e características, bem como a metodologia de trabalho. O segundo apresenta, discute e questiona os dados apresentados da realidade urbana em Palmas por meio dos indicadores bem como a priorização dos temas para as ações, considerando, além da avaliação dos indicadores, também os quatro filtros apresentados pela metodologia ICES.

Por fim, demostra existir pontos de tensão entre os conceitos de desenvolvimento e justiça social e a prática adotada para elaboração do diagnóstico e priorização dos temas, principalmente no que tange à representatividade da participação nos processos de tomada decisão.

\section{Desenvolvimento e a justiça social em debate}

Para compreender os pressupostos teóricos acerca do desenvolvimento e da justiça social utilizados no processo de elaboração do diagnóstico do Plano de Ação Palmas Sustentável foi necessário estruturar uma base teórica capaz de embasar as análises.

Heidemann (2009), esclarece que a busca pelo progresso nasce no Século XVII. Naquele período, a ideia do progresso significava que os acontecimentos históricos passavam por um aperfeiçoamento crescente, desenvolvendo-se de maneira mais desejável com o passar do tempo. O autor afirma que nas primeiras décadas do Século XX, a promoção do progresso estava, principalmente, a cargo das forças da economia de mercado sob o comando teórico da economia política. O Estado praticamente não tinha um papel a exercer em relação à economia e tampouco existia uma política de progresso nos moldes das políticas de desenvolvimento da atualidade. Desse modo, sem a ação e interferência do Estado "regulando politicamente a economia, não havia política pública para estabelecer contornos e condicionar as ações econômicas que dependiam, pois, quase exclusivamente de um mercado autorregulado" (HEIDEMANN, 2009, p. 25).

Então, no período entre as duas guerras mundiais, o papel do Estado cresceu e, consequentemente, a importância do mercado autorregulado diminuiu. Os Estados e os mercados passaram a buscar juntos o desenvolvimento das sociedades. Foi naquele momento, então, que apareceram as chamadas políticas governamentais, mais tarde entendidas melhor como políticas públicas. No Brasil, até a metade do Século XX, não se usava o conceito institucional abrangente e 
integrador de desenvolvimento. $\mathrm{O}$ esforço de industrialização não fazia parte de um projeto de desenvolvimento integrado que levasse em conta outras preocupações sociais como educação, saúde e meio ambiente. A ideia de desenvolvimento foi semeada e cultivada como projeto político no Brasil após a II Guerra Mundial.

Souza (2010), afirma que as discussões sobre desenvolvimento, ainda na contemporaneidade, apresentam o vício de tratá-lo como sinônimo de desenvolvimento econômico e modernização da sociedade, principalmente por compreender o processo histórico descrito anteriormente. Boisier (1999), traz a ideia introduzida por Seers, enfatizando que o desenvolvimento significa a redução da pobreza, do desemprego e da inequidade e deve ser entendido como o resultado de certo consenso social. Nesse contexto, Boisier afirma ser importante conhecer as articulações específicas entre crescimento econômico e desenvolvimento "atribuindo, ao primeiro, a mera condição de necessário, mas nunca suficiente" (BOISIER, 1999, p. 325).

Heidemann (2009), ressalta que os efeitos negativos do desenvolvimento, as consequências indesejadas e imprevistas levaram os pesquisadores a estudar e reavaliar seus modelos e a pensar que a noção do desenvolvimento, sem qualificações, não era mais satisfatória, sendo necessário questionar que desenvolvimento. A resposta que se segue é de uma longa lista de adjetivos empregados para descrever o desenvolvimento desejado e desejável.

Ao tratar de desenvolvimento regional, Boisier (1996) conceitua região como "quase Estado", no sentido de evidenciar a questão do poder político, ou seja, a dimensão política do desenvolvimento regional em primeiro lugar. O argumento é o seguinte: "todas as regiões se encontram, a todo momento, articuladas entre si por relações de dominação e dependência, hierarquicamente ordenadas" (BOISIER, 1996, p. 122). Segundo o autor, essas relações são fruto de um controle assimétrico do poder político e que, para romper a relação de dominação, uma região precisa acumular poder político. Entretanto, a questão permanece em entender como uma região pode acumular poder político. O referido autor ressalta a criação de um projeto de desenvolvimento articulado em dois processos para resolver tal problema:

[...] o primeiro, pela transferência de poder político incorporada em um projeto nacional descentralizador (...), e segundo, por meio da criação de poder político, algo que se obtém mediante o consenso político, o pacto social, a cultura da cooperação e a capacidade de criar, coletivamente, um projeto de desenvolvimento. Eis, portanto, a relevância do conceito de projeto político regional como instrumento de criação de poder político" (BOISIER, 1996, p. 124) (grifo nosso). 
Nesse ponto de vista, o autor afirma a importância de consenso político, pacto social e cultura da cooperação como meios para a sociedade criar, coletivamente, seu projeto de desenvolvimento. Tal perspectiva corrobora com outros entendimentos do que seria desenvolvimento.

Para Souza (2010), o desenvolvimento deve ser entendido como uma mudança social positiva e de conteúdo atrelado aos desejos e expectativas de grupos sociais concretos, considerando seus valores culturais e particularidades históricogeográficas. Desse modo, "se está diante de um autêntico processo de desenvolvimento socioespacial quando se constata uma melhoria da qualidade de vida e um aumento da justiça social" (SOUZA, 2010, p. 61). O autor reforça no conceito de desenvolvimento socioespacial a categoria do espaço, pois a mudança social positiva precisa contemplar não apenas as relações sociais, mas também a espacialidade. Para ele, o espaço não pode ser negligenciado nas análises relativas ao desenvolvimento em suas dimensões de lugar e território, pois é o palco da vida dotado de significados, a arena das relações sociais, a fonte dos recursos físicos e materiais e referencial simbólico de localização e condicionador de processos sociais.

A melhoria da qualidade de vida se traduz na crescente satisfação das necessidades, tanto básicas e materiais, como não básicas e imateriais de uma parcela cada vez maior da população. Para Maricato et al. (2013), nem toda melhoria das condições de vida é acessível com melhores salários ou com melhor distribuição de renda. A autora coloca que boas condições de vida dependem, na maioria das vezes, de políticas públicas urbanas de transporte, moradia, saneamento e de locação de equipamentos como educação, saúde, lazer, a qualidade dos serviços, de iluminação pública, coleta de lixo e de segurança.

No que tange ao aumento da justiça social, Souza (2010) destaca a complexidade da multiplicidade de entendimentos da ideia de justiça social. Para ele, esta noção calibra e contextualiza a melhoria da qualidade de vida. Pizzio (2016, p. 356), coaduna com essa ideia ao afirmar que o "enfrentamento dos aspectos que envolvem a ideia de justiça social constitui uma tarefa árdua".

O autor apresenta em seu estudo diversas referências teóricas acerca da justiça social em um primeiro momento considerando critérios distributivos em relação à riqueza socialmente produzida e aos seus benefícios. Num segundo momento, pondera sobre o reconhecimento como elemento fundamental nos debates acerca da identidade e da diferença, considerando uma abordagem cultural (PIZZIO, 2016). Na sequência, traz à discussão a tridimensionalidade da justiça social na perspectiva de Nancy Fraser (2008), que desenvolve um novo paradigma de justiça social que integre as duas reivindicações.

Fraser (2008), contribui para a compreensão do que seria justiça social apresentando três dimensões a serem consideradas neste artigo: a primeira é a econômica da distribuição; a segunda é a cultural do reconhecimento e a terceira, a 
dimensão política da representação. Para a autora, a globalização mudou a maneira de se falar de justiça social e fez surgir o desafio importante de se pensar neste conceito para além das duas primeiras dimensões: distribuição e reconhecimento. Para ela,

[...] o político é entendido em um sentido mais específico e constitutivo, que remete à natureza da jurisdição do Estado e às regras de decisão com que se estrutura a confrontação. Nesse entendimento, o político é o cenário no qual se desenvolvem as lutas por distribuição e reconhecimento. Ao estabelecer os critérios de pertencimento e ao determinar quem conta como membro, a dimensão política da justiça especifica o alcance das outras dimensões. Ela informa quem faz parte ou não do grupo dos que têm direito a uma justa redistribuição ou ao reconhecimento mútuo (PIZZIO, 2016, p. 367).

Portanto, superar a injustiça, na visão da autora, significaria desmantelar os obstáculos institucionalizados que impedem alguns de participar, visto que nas sociedades capitalistas modernas a estrutura de classes e o baixo reconhecimento cultural ainda se mostram como uma barreira à paridade de participação.

Para reforçar a terceira dimensão, que é a política, ela afirma que esta fornece o cenário onde se desenvolvem as lutas por distribuição e reconhecimento. Ao estabelecer os critérios de pertencimento social, a dimensão política da justiça especifica o alcance das outras duas dimensões, pois diz quem está ou não incluído. Em igual medida, ao estabelecer as regras de decisão, a dimensão política disciplina também os procedimentos de resolução dos conflitos (FRASER, 2008).

A autora afirma, ainda, que a dimensão política não apenas indica quem tem o direito a reivindicar redistribuição e reconhecimento, mas também como estabelece e avalia essas reivindicações. Nessa perspectiva, a dimensão política da justiça se interessa sobretudo pela representação, sendo a injustiça política a representação falida, ou seja, quando os limites políticos e as regras de decisão negam a determinados indivíduos a possibilidade de participar em paridade nos processos de interação social. Neste sentido, ela propõe a paridade de participação, pois a busca pela justiça social requer que todos os membros da sociedade tenham possibilidade de interagir com os pares. Assim, a paridade na participação seria o caminho para ações que reforcem a construção coletiva do pacto social em torno de um projeto coletivo de desenvolvimento socialmente gestado.

Neste sentido, Evans (2003) defende que as instituições básicas de governança constituem o elemento-chave para fomentar o desenvolvimento. Para o autor, o desenvolvimento dos países pobres somente seria possível por meio da construção de um conjunto de instituições adaptadas para superar as armadilhas da pobreza e as desvantagens cumulativas de ser um país pobre. 
Ele ressalta que o padrão das políticas públicas em países em desenvolvimento tem sido historicamente a insistência na monocultura institucional, que se baseia em duas premissas: a eficiência das instituições não depende do ambiente sociocultural e que a versão idealizada de instituições anglo-americanas é a ideal para o desenvolvimento local. $\mathrm{O}$ autor afirma, ainda, que as organizações internacionais pregam a presunção de que "os países mais avançados já descobriram o melhor planejamento institucional para o desenvolvimento e de que sua aplicabilidade transcende culturas e circunstâncias nacionais" (EVANS, 2003, p. 28).

Para o autor, a possibilidade de fugir da armadilha da monocultura institucional e pensar estratégias alternativas é buscar instituições participativas como, por exemplo, meta-instituições que promovam e agreguem conhecimento local e, desse modo, tornem possível construir instituições políticas melhores e adaptadas à realidade do ambiente sociocultural. A implantação desse tipo de processo deliberativo em escala suficientemente ampla, como a municipal, levaria ao desenvolvimento deliberativo. Ele afirma que a democracia deliberativa, ou seja, processos participativos de planejamento e solução de problemas, é o caminho mais eficiente e eficaz a longo prazo de se alcançar o desenvolvimento, sendo as instituições deliberativas centrais em qualquer conceituação de desenvolvimento.

As ideias de Fraser (2008) e Evans (2003) coadunam com Boisier (1996) quando enfatizam a questão do pacto social, a cultura da cooperação e a capacidade de criar coletivamente um projeto de desenvolvimento. Também com Souza (2010), quando ele apresenta o desenvolvimento urbano de maneira mais ampla do que a simples complexificação do tecido urbano e associado ao desenvolvimento socioespacial, ou seja, tendo na melhoria da qualidade de vida e na justiça social seus objetivos derivados. Ele acentua que, para alcançar esse tipo de desenvolvimento, a experiência prática do cotidiano e o saber local dos cidadãos devem ser incorporados à intervenção planejadora e gestora. Os atores sociais, na qualidade de consultores populares, podem definir os parâmetros da qualidade de vida por meio da justiça social.

Nos itens seguintes há os conceitos sobre desenvolvimento em sua abordagem socioespacial urbana e sobre justiça social como instrumentos para as análises realizadas. Discute-se também a ICES, seus objetivos e características bem como a metodologia de trabalho. Posteriormente são apresentados os dados da realidade urbana em Palmas por meio dos indicadores e a priorização dos temas para as ações, considerando, além da avaliação dos indicadores, também os quatro filtros apresentados pela metodologia ICES. 


\section{Sobre a ICES e sua metodologia}

Neste item é apresentada a análise e discussão sobre a construção do diagnóstico do Plano de Ação Palmas Sustentável (2015), considerando a metodologia e objetivos da Iniciativa Cidades Emergentes e Sustentáveis (ICES). No documento Plano de Ação Palmas Sustentável (2015), a ICES é apresentada como um programa de assistência técnica voltado aos governos das cidades médias da América Latina e Caribe (ALC) criado pelo BID. Tem como justificativa o rápido crescimento urbano, a concentração das atividades econômicas e os desafios dos "governos locais na provisão de serviços básicos, na garantia de níveis adequados de qualidade de vida, na redução das desigualdades, na geração de empregos, na proteção do meio ambiente" (PALMAS, 2015, p. 33). Observa-se que mesmo incluindo niveis adequados de qualidade de vida e a redução das desigualdades, o documento não se aprofunda nesse aspecto, não detalha quais seriam os níveis adequados de qualidade de vida nem qual tipo de desigualdade pretende reduzir.

No Plano é apresentado também que, para a ICES, uma cidade emergente é aquela com área urbana de tamanho médio e que demonstra "crescimento populacional e econômico acima da média em seu país" (PALMAS, 2015, p. 36). Adverte, ainda, que as cidades médias vêm crescendo em uma taxa maior do que as grandes, principalmente na ALC. No Brasil, a ICES iniciou em Goiânia, ainda em sua fase piloto, em 2011. A partir de 2013, foi firmada a parceria entre o BID e a Caixa e houve a expansão da iniciativa em mais outras quatro cidades, contemplando as cinco regiões do país. Goiânia (GO), na região Centro-Oeste; João Pessoa (PB), na região Nordeste; Vitória (ES), na região Sudeste; Florianópolis (SC), na região Sul e Palmas (TO), na região Norte.

Quando apresenta as razões para a inclusão de Palmas na ICES, o Plano afirma que o município passa por "forte movimento de expansão e adequação de sua infraestrutura para atender as demandas de seu crescimento" (PALMAS, 2015, p. 41). Posteriormente, coloca que Palmas possuiu uma alta taxa média de crescimento anual de 2000 a 2010 e enfatiza as questões da urbanização dispersa e da baixa densidade demográfica. Desse modo, ressalta-se que o forte movimento de expansão se refere ao aumento do perímetro urbano com a ampliação das fronteiras da cidade e da sua área urbana visto que, mesmo com aumento populacional considerável, a cidade continua com baixa densidade demográfica.

Na sequência, o Plano chama a atenção ao trazer o indicador de desenvolvimento humano como um importante dado para demonstrar as qualidades da cidade de Palmas e coloca:

Palmas registrou a maior taxa de crescimento no Índice de Desenvolvimento Humano (IDH) entre todas as 27 capitais do País no período entre 1991 e 2010. Em 1991, Palmas tinha o pior IDH entre as 
capitais, com 0,439, atingindo um indice de 0,788 em 2010 e saltando para a $10^{a}$ posição no ranking nacional. A qualidade do sistema público de educação e de saúde, bem como a renda per capita acima da média nacional, $12^{\mathrm{a}}$ entre as capitais em 2010 segundo o IBGE, são alguns dos pontos que, tradicionalmente, associam Palmas à imagem de uma cidade próspera e com desenvolvimento adequado (PALMAS, 2015, p. 19) (grifo nosso).

Cabe discutir um ponto importante sobre essas afirmações. A composição do indicador de Índice de Desenvolvimento Humano (IDH) inclui o dado de renda per capita, informação que em nada contribui para a compreensão sobre desigualdade socioeconômica da população. É possível que a cidade de Palmas tenha uma alta renda per capita concentrada em uma pequena parcela da população, como bem demostra o próprio Plano, na citação a seguir.

No entanto, apesar do bom desempenho dos indicadores socioeconômicos, constata-se que há uma desigualdade urbana muito alta em Palmas, visto que o município apresenta uma renda bastante concentrada. Tal desigualdade pode ser constatada a partir do confronto entre o índice de GINI e do PIB per capita. Apesar de em 2010, o PIB per capita situar-se acima de US $\$ 9.000$, o índice de Gini $(0,55)$ atesta a persistência da desigualdade distributiva (PALMAS, 2015, p. 44) (grifo nosso).

O Plano assume ainda que além da baixa densidade de ocupação e o espraiamento da expansão urbana, a "precariedade habitacional e a segregação socioespacial são desafios que a administração pública municipal precisará enfrentar na busca da diminuição da desigualdade urbana" (PALMAS, 2015, p. 44). Aqui observa-se pela primeira vez no documento o reconhecimento dos problemas relativos à desigualdade urbana e distributiva da renda demonstrados nas condições precárias de vida de parcela da população e na alta segregação socioespacial apresentada pela cidade, problemas urbanos que aparecem como principais na cidade de Palmas.

Apresenta ainda que "Palmas, apesar de seu crescimento e desenvolvimento recente, não está livre dos riscos que a concentração de renda impõe, como, por exemplo, o aumento da desigualdade urbana e do crescimento dos índices de violência" (PALMAS, 2015, p. 44). A contradição no entendimento do desenvolvimento recente em Palmas, que ainda se mantém, reforça e aumenta as desigualdades. Qual modelo de desenvolvimento é esse? Apenas aquele relacionado aos aspectos econômicos?

Nesse ponto, é possível recuperar a afirmação de Souza (2010), de que a compreensão sobre desenvolvimento deve pressupor o aumento da justiça social. 
A desigualdade urbana demonstrada e reconhecida pelo Plano em Palmas compromete a utilização simplificada de informações como o crescimento e dinamismo econômico, a renda per capita e IDH para identificar características de desenvolvimento urbano de uma cidade. Contribui, desta maneira, para refutar a associação de Palmas "à imagem de uma cidade próspera e com desenvolvimento adequado" (PALMAS, 2015, p. 19).

Desse modo, cabe ressaltar que o entendimento de justiça, em sua abordagem material, trata os termos da identificação de critérios adequados em relação à distribuição da riqueza socialmente produzida aos seus beneficiários. Assim, "a discussão sobre o que é justo ou injusto, particularmente em relação à partilha de recompensas e ônus sociais, encontra-se permeada pelo debate sobre a igualdade e a desigualdade na distribuição de bens sociais" (PIZZIO, 2016, p. 357).

Posteriormente, observa-se a apresentação da metodologia realizada pela ICES defendida como uma "avaliação rápida que permite a identificação e priorização de projetos de infraestrutura, assim como a definição de ações urbanas, ambientais, sociais, fiscais e de governança de curto, médio e longo prazo" (PALMAS, 2015, p. 19). Nesse sentido, a metodologia seria capaz de propor ações que visam enfrentar os desafios de sustentabilidade local antes que se tornem um problema ao desenvolvimento. É apresentada uma abordagem interdisciplinar baseada em três dimensões: ambiental e mudança climática, urbana, fiscal e governança. A velocidade da avaliação expressada na metodologia sugere o risco de formar uma avaliação apressada e superficial.

"No caso da ICES em Palmas, a primeira fase envolveu a seleção e contratação do Instituto Pólis para a aplicação da Iniciativa na cidade com os recursos disponibilizados pelo Fundo Socioambiental da Caixa" (PALMAS, 2015, p. 52). A aplicação da metodologia parte da elaboração de um diagnóstico rápido de 120 indicadores (no caso de Palmas, foram utilizados 117) agrupados em 23 temas e divididos nas três grandes dimensões citadas.

O Plano ressalta que "os indicadores são complementados com um diagnóstico mais abrangente sobre diferentes temas realizado por um grupo de especialistas e acompanhado pela prefeitura, BID e Caixa" (PALMAS, 2015, p. 52). Após o diagnóstico dos indicadores, os valores obtidos foram comparados com os parâmetros propostos pelo BID para a América Latina e Caribe. Depois dessa comparação, cada indicador foi classificado pelas cores do semáforo. O vermelho foi utilizado para os indicadores considerados críticos, o amarelo quando estão em alerta e verde para aqueles em situação positiva.

Ressalta-se, aqui, que o diagnóstico foi realizado por um grupo de especialistas acompanhado pela prefeitura, BID e Caixa. Os dados foram comparados com parâmetros propostos pelo BID. Uma pergunta pertinente é se esse processo comparativo leva em consideração as especificidades culturais, históricas e geográficas das cidades da ALC. 
Vale destacar também o fato de que os padrões de qualidade de vida não são necessariamente os mesmos em todos os lugares. A padronização das demandas é contrária à lógica da busca por um desenvolvimento urbano apoiado no aumento da justiça social visto que, além da igualdade distributiva, a igualdade pelo reconhecimento também compõe uma das dimensões da justiça social (FRASER, 2008; PIZZIO, 2016). Essa dimensão se mostra particularmente importante no processo de busca por um desenvolvimento apoiado nas características da escala do local. Nessa perspectiva, é primordial compreender e reconhecer as peculiaridades de uma sociedade, suas necessidades e demandas específicas. Possibilitando, assim, a fuga da armadilha da monocultura institucional, partindo para estratégias alternativas que agreguem o conhecimento local, conforme apresentado por Evans (2003).

A fase seguinte, a de priorização "envolve[u] a equipe técnica do BID, da Caixa, da prefeitura, entidades parceiras e outros atores-chave da cidade" (PALMAS, 2015, p. 52). Nela, os temas mais críticos para a sustentabilidade da cidade receberam prioridade com base na aplicação de quatro filtros: Opinião Pública ${ }^{1}$, que mede a importância que os cidadãos conferem a cada um dos temas; custo econômico, que analisa os efeitos dos temas sobre o PIB, emprego e competitividade; ambiental/mudança climática, que relaciona a vulnerabilidade à mudança climática e níveis de emissão de gases de efeito estufa e valoração dos especialistas (BID, 2012; PALMAS, 2015). Para o projeto ICES Palmas, a aplicação e a consolidação dos filtros foram realizadas por meio de um sistema de priorização on-line. O Sistema WebICES recebeu as informações do semáforo de indicadores e dos filtros, gerando o resultado consolidado.

Os filtros assinalam uma pontuação de 1 a 5 para cada área temática, onde 1 é a prioridade mais baixa e 5 é a prioridade mais alta. Após a consolidação dos filtros, os temas com a pontuação total mais alta são discutidos entre a prefeitura, a Caixa e o BID para deliberação e validação em um seminário de áreas priorizadas realizado na cidade (PALMAS, 2015, p. 139).

\footnotetext{
1 Segundo o Plano de Ação Palmas Sustentável (PALMAS, 2015), a Pesquisa de Opinião Cidadã foi feita entre os dias 9 e 28 de janeiro de 2015 e entrevistou 1.007 pessoas distribuídas entre as 10 regiões administrativas do município de Palmas, buscando colher a percepção dos moradores sobre os temas abordados pela ICES. Tal divisão respeitou os critérios de população e controle administrativo do município de Palmas. O questionário continha 124 perguntas divididas em 22 blocos e 10 campos de Caracterização do Entrevistado. Parte dos resultados foi espacializado no território, permitindo a elaboração de mapas. Essas informações serviram para complementar as análises temáticas dos especialistas e os debates técnicos e também compuseram um dos filtros aplicados sobre os indicadores da ICES em Palmas.
} 
O Plano afirma que "os temas tratados pelo diagnóstico foram também avaliados pela população local por meio da Pesquisa de Opinião Pública, trazendo ao conhecimento dos técnicos a percepção da sociedade sobre cada um dos temas" (PALMAS, 2015, p. 59). O filtro Opinião Pública foi baseado nos resultados dessa Pesquisa de Opinião Pública realizada em 2015 no município de Palmas, por meio da qual foram entrevistados 1.007 cidadãos. Destaca-se, segundo o Plano, que "os temas 'Competitividade da economia', 'Impostos e autonomia financeira', 'Gestão do gasto público' e 'Dívida' não foram abordados no questionário da pesquisa” (PALMAS, 2015, p. 143).

O filtro Ambiental foi preenchido a partir dos dados coletados e analisados pelo consórcio IDOM-Cobrape. Os filtros Técnico e o Econômico foram preenchidos pelos especialistas do Instituto Pólis, técnicos da Caixa local, BID e prefeitura municipal de Palmas. Para a priorização, cada uma das avaliações recebeu uma ponderação diferente. O semáforo recebeu o peso de 40\%, o filtro Opinião Pública recebeu peso de 30\%, o filtro Ambiental, Técnico e o Econômico receberam pesos de $10 \%$ cada um, totalizando os $100 \%$ do processo de priorização por meio dos filtros.

Cabe destacar que o filtro Opinião Pública somente interferiu em 30\% no processo de priorização, visto que os demais $70 \%$ são frutos de estudos e filtros realizados por especialistas. Questiona-se, então, se não há nesta metodologia uma assimetria no processo participativo. A dimensão política da justiça social, por meio da representação e do direito de participar, foi realmente considerada?

Nota-se que somente na elaboração de um dos filtros, de peso 30\%, houve participação popular. Desse modo, observa-se que a não paridade de participação leva à configuração de uma representação falida (FRASER, 2008), pois as regras estabelecidas quanto aos pesos dos filtros para a tomada de decisão relativa à priorização dos temas privilegiaram sobremaneira o trabalho dos especialistas, negando de maneira prática a participação popular por meio da Pesquisa de Opinião. Nesse sentido, o próximo item se dedica a apresentar a visão de cidade construída pelos indicadores e como foi o processo de priorização dos temas por meio da aplicação dos filtros.

\section{A visão da cidade apresentada pelos indicadores}

Neste item é apresentada a análise e discussão sobre a construção do diagnóstico do Plano de Ação Palmas Sustentável (2015), considerando principalmente a visão da cidade apresentada por meio da avaliação por indicadores e a priorização dos temas. Segundo a Metodologia ICES, a primeira fase para a avaliação da realidade urbana da cidade é referente à construção de um diagnóstico de indicadores em 23 temas, em três dimensões, em Palmas, desenvolvido pela consultoria do Instituto Pólis. 
Em seguida, os valores obtidos pelo diagnóstico dos indicadores foram comparados com os parâmetros propostos pelo BID para a América Latina e Caribe e classificados pelo exercício do semáforo, que sinaliza os indicadores em vermelho para os considerados críticos, em amarelo quando estão em alerta e em verde para aqueles em situação positiva (Quadro 1).

Quadro 1 - Temas do diagnóstico com as cores do semáforo

\begin{tabular}{|l|l|l|}
\hline Dimensão & Tema & Avaliação \\
\hline \multirow{5}{*}{ Fiscal e governança } & Dívida & Verde \\
\cline { 2 - 3 } & Gestão de gastos públicos & Amarela \\
\cline { 2 - 3 } & Impostos e autonomia financeira & Vermelha \\
\cline { 2 - 3 } & Transparência & Amarela \\
\cline { 2 - 3 } & Gestão pública moderna & Vermelha \\
\cline { 2 - 3 } & Gestão Pública participativa & Amarela \\
\hline \multirow{5}{*}{ climb́ticas } & Água & Verde \\
\cline { 2 - 3 } & Esgotamento sanitário e drenagem & Amarela \\
\cline { 2 - 3 } & Gestão de resíduos sólidos & Amarela \\
\cline { 2 - 3 } & Energia & Amarela \\
\cline { 2 - 3 } & Qualidade do ar & Amarela \\
\cline { 2 - 3 } & Mitigação de mudanças climáticas & Amarela \\
\cline { 2 - 3 } & Ruído & Amarela \\
\cline { 2 - 3 } & Vulnerabilidade diante de desastres naturais & Amarela \\
\hline \multirow{5}{*}{ Desenvolvimento urbano } & Verde \\
\hline & Saúde & Amarela \\
\cline { 2 - 3 } & Segurança & Amarela \\
\cline { 2 - 3 } & Educação & Verde \\
\cline { 2 - 3 } & Conectividade & Amarela \\
\cline { 2 - 3 } & Emprego & Vermelha \\
\cline { 2 - 3 } & Competitividade econômica & Vermelha \\
\cline { 2 - 3 } & Mobilidade e transporte & Amarela \\
\hline & Desigualdade urbana & \\
\cline { 2 - 3 } & Uso do Solo e Ordenamento Territorial & \\
\hline
\end{tabular}

Fonte: Palmas, 2015. Adaptado pelos autores.

Vale comentar que os temas água, conectividade, saúde e gestão adequada da dívida apresentaram avaliação na cor verde, embora, segundo o próprio Plano, a questão relativa à eficiência no serviço de abastecimento de água mereça atenção em função da perda na distribuição de água tratada.

Destaca-se, também, que mesmo o índice de conectividade tendo sido considerado verde, há um importante dado a ser avaliado: a "exceção feita ao número de assinaturas de internet de banda larga fixa com apenas 11,51 assinaturas por 100 habitantes" (PALMAS, 2015, p. 64). Os acessos realizados por internet móvel através de celulares foram avaliados em verde, mas permanece uma porcentagem baixa quando contabilizada somente a internet de banda larga. 
O Plano evidencia que "a saúde foi o único tema com todos os seus indicadores em verde" (PALMAS, 2015, p. 59), entretanto, existe uma importante contradição nos dados coletados na fase de diagnóstico e a Pesquisa de Opinião Pública aplicada na cidade. Nessa última, a saúde foi apontada como a principal situação que poderia afetar a qualidade de vida da população, sendo registrado como principal setor que deveria ser priorizado ${ }^{2}$. Os indicadores realizados pelos especialistas apresentam todos os pontos em verde, quando na percepção da população há preocupação sobre ele, sendo considerado vermelho.

Em vermelho aparecem, na dimensão de fiscal e governança, os temas impostos e autonomia financeira e gestão pública moderna. Na dimensão de desenvolvimento urbano, aparece em vermelho a competitividade da economia, a mobilidade e transporte e a desigualdade urbana. Cada um desses pontos será discutido a seguir.

O item relativo aos impostos e autonomia financeira foi objeto também do Filtro Econômico, que levou em consideração dados como a participação dos diferentes setores econômicos no Produto Interno Bruto (PIB) e na geração de empregos. A ICES considera a autonomia financeira municipal um instrumento fundamental para a definição de políticas públicas com recursos próprios.

Em relação ao percentual das receitas próprias sobre o total das receitas no município de Palmas, no ano de 2012, a receita própria representou apenas $35 \%$ da receita total do município naquele ano, enquanto a média de participação das capitais foi de 44\% pontos percentuais, assumindo a sétima posição no ranking em relação aos piores resultados (PALMAS, 2015, p. 98).

Desse modo, o Plano considerou que, comparada às demais capitais, Palmas tem uma grande dependência das transferências constitucionais e voluntárias no orçamento de 2012. Essas transferências totalizaram 65\% dos recursos disponíveis. O Plano ressalta ainda que essa dependência pode limitar a autonomia e a capacidade de gestão e promoção das políticas públicas por parte da municipalidade.

Quanto ao item gestão pública moderna, o Plano destaca o tempo de vigência do orçamento municipal de somente um ano como um ponto problemático, ainda que a gestão pública não disponibilize um sistema de prestação de contas que meça os avanços e resultados da gestão. Nesse sentido, somente o Portal da Transparência e o Diário Oficial são utilizados para disponibilizar informações para a população. $\mathrm{Na}$ visão da ICES, seriam necessárias mais informações "para o acompanhamento da prestação de contas dos bens e serviços realizados durante a execução orçamentária” (PALMAS, 2015, p. 98). O aprimoramento do sistema de

\footnotetext{
${ }^{2}$ Essa contradição será melhor apresentada posteriormente quando é feita a apresentação da priorização dos temas.
} 
remuneração de pessoal também é um ponto destacado no Plano como necessário para maior eficiência na gestão pública. Seria preciso o desenvolvimento de um instrumento que permita além da prestação de contas, a avaliação dos avanços e resultados da gestão municipal e das compras realizadas.

Quando trata da baixa competitividade da economia local, o plano ressalta que no município não há integração entre as atividades e serviços para realização de uma plataforma logística, podendo ser utilizada área do aeroporto, integrando-o com os demais modais.

Estes três itens em vermelho: impostos e autonomia financeira, gestão pública moderna e competitividade da economia parecem estar inter-relacionados, principalmente por considerarem a autonomia financeira e a gestão pública moderna o caminho para alcançar maior e melhor competitividade. A busca por um desenvolvimento regional, na concepção apresentada por Boisier (1996), pressupõe relações de dominação e dependência hierarquicamente ordenadas que privilegiam regiões de maior competitividade econômica.

Quanto ao item desigualdade urbana, o plano destaca que a porcentagem da população abaixo da linha de pobreza divulgada pelo Atlas de Desenvolvimento Humano no Brasil, cuja fonte é o Programa das Nações Unidas para o Desenvolvimento (PNUD), foi de 6,91\%. Entretanto informações do censo demográfico apontam para a existência de $29,4 \%$ de pessoas abaixo da linha da pobreza. A grande diferença entre os dados sugere a necessidade de mais estudos e pesquisas que possam de fato esclarecer a realidade da vida da população palmense, o que leva a questionamentos importantes. Como propor uma política pública de qualidade quando não se sabe o tamanho da demanda a ser atendida?

O Plano de Ação (2015), que apresenta dados do Plano de Regularização Fundiária do Município de Palmas de 2009, indica que 26,2\% das moradias estão em assentamentos informais, ou seja, em vulnerabilidade. A Pesquisa de Opinião Pública mostrou que $67,5 \%$ da população considera a renda da família suficiente para cobrir suas necessidades. Nas informações disponíveis para o ano de 2010 (IBGE), mesmo a renda média sendo de $\mathrm{R} \$ 1.630,42$, apenas $30 \%$ das pessoas com melhores remunerações recebem renda acima de $\mathrm{R} \$ 1.500,00$. Isso reforça mais uma vez a ineficiência dos dados de renda per capita quando dissociados dos dados de concentração de renda.

Sobre o item mobilidade e transporte, as informações são que, devido aos desvios na estratégia de implantação da cidade e ao processo desordenado da ocupação, "houve espalhamento da cidade, grandes vazios urbanos, infraestrutura subutilizada e expulsão da população de baixa renda para a área periférica do município, principalmente na região sul" (PALMAS, 2015, p. 95). O Plano ressalta que há alta dispersão urbana e um privilégio ao transporte individual e, ainda, nenhuma via com tratamento prioritário para o transporte coletivo e extensão mínima de ciclovias. Nesse sentido, reforça que, mesmo com a falta de 
infraestrutura para o uso de bicicletas e da malha urbana espraiada, é comum a presença de ciclistas nas ruas da cidade que, por falta de espaço seguro, expõem-se a risco de acidentes. A soma de todos esses fatores faz dos indicadores de mobilidade em Palmas ruins, bem como na maioria das cidades brasileiras.

Recebe destaque no Plano o projeto do Bus Rapid Transit (BRT) ou Transporte Rápido por Ônibus, no momento em fase de desenvolvimento.

A prefeitura está desenvolvendo um projeto para implantação de um corredor exclusivo para ônibus (BRT) ao longo da Av. Teotônio Segurado em direção a Palmas Sul. Com a operação desse novo sistema, o indicador de extensão de corredores por 100 mil babitantes passará para 11,3, ainda muito distante da classificaçãa verde (PALMAS, 2015, p. 95) (grifo nosso).

Esse projeto teve o orçamento avaliado em aproximadamente $\mathrm{R} \$ 500$ milhões $^{3} \mathrm{e}$ foi objeto de processo na Justiça Federal e auditoria pelo Tribunal de Contas da União (TCU), o que levou a não efetivação. A auditoria do TCU observou irregularidades no processo por considerar a demanda e a necessidade do sistema superestimadas devido deficiências nos estudos de viabilidade técnica, econômica e ambiental. Importante notar que o próprio Plano afirma que, mesmo com esse projeto de valor tão elevado, ele não seria capaz de alterar o cenário do indicador de mobilidade para a classificação verde.

Assim, para realmente melhorar as condições de transporte em Palmas, é importante considerar outros fatores como a condição dos pedestres, que necessitam de calçadas nas vias públicas e do privilégio de faixas de rolagem exclusivas para o transporte coletivo. Ainda merecem atenção e melhoria os pontos apresentados na Pesquisa de Opinião Pública, a saber:

[...] a avaliação quanto à frequência dos ônibus foi 'regular'(...). O preço da passagem, a comodidade, a limpeza, a lotação, o tempo de viagem, o comportamento dos motoristas e a condição dos pontos de parada também foram qualificados como 'regulares' (PALMAS, 2015, p. 97).

\footnotetext{
3 "O projeto apresentado dividia o sistema do BRT em dois trechos: o da região sul, que tinha crédito de $\mathrm{R} \$$ 227.915.304,00, de recursos da União. E o trecho central do sistema, para o qual a prefeitura conseguiu financiamento de R \$226.550.000,00 junto à Caixa Econômica Federal. Os dois financiamentos foram bloqueados pela Justiça. O primeiro em outubro de 2015 e o segundo em dezembro do mesmo ano. Para o relator do processo no TCU, o ministro-substituto André Luís de Carvalho, 'a ausência de comprovação da viabilidade do empreendimento acarreta risco potencial de prejuízo ao erário, na medida em que os recursos públicos podem vir a ser aplicados em projeto assentado em premissas superestimadas e desconformes à realidade dos fatos'." (G1 TO, 2017).
} 
A configuração da área urbana do município - espalhada e de baixa densidade afeta também os custos operacionais do transporte coletivo e prejudica o resultado econômico do serviço. Relativo ao preço da passagem, o Plano destaca que, em Palmas, os gastos com transporte apresentam um peso excessivo no orçamento familiar e "representam 92,8\% da renda per capita do quintil mais pobre da população, muito superior ao de todas as cidades pares” (PALMAS, 2015, p. 96).

Todos os demais temas foram apresentados em amarelo. Destacam-se alguns pontos, como o tema de uso do solo e ordenamento territorial, que apresenta uma taxa de crescimento anual da malha urbana de 6\%. Consta que $28 \%$ das moradias não respeitam os padrões de habitabilidade. O tema emprego apresenta a taxa de emprego informal de $34 \%$ e taxa de desemprego de 6,58\%. O tema educação mostra um déficit no atendimento da demanda por matrículas de aproximadamente 5 mil vagas. O tema segurança indica que apenas $18 \%$ da população afirma se sentir segura na cidade. Quanto à gestão pública participativa, no Plano não há orçamento participativo e o planejamento não é participativo.

Esses pontos reforçam a questão já levantada quanto aos padrões de comparação para a classificação dos itens em cores. Alguns desses números apresentados no documento merecem bastante atenção, um deles reforçado pela Opinião Pública referente à segurança em que $81 \%$ dos moradores entrevistados não se sentiam seguros caminhando sozinhos à noite na cidade. Ainda na questão habitacional, destaca-se que " $28,2 \%$ das moradias não respeitam os padrões mínimos de habitabilidade e $18,19 \%$ das moradias precisam ser substituídas por novas" (PALMAS, 2015, p. 85).

Todos esses dados precisam ser melhor avaliados para garantir a confiabilidade em seus números, permitindo que as políticas públicas possam ser planejadas sobre a demanda real. Ainda há a necessidade de que a própria população, por meio de processo de deliberação participativa, possa definir os parâmetros para classificar a gravidade desses números e eleger de maneira mais direta suas prioridades.

A metodologia apresentada para a ICES (BID, 2012; PALMAS, 2015), mesmo colocando a Pesquisa de Opinião Pública como um importante trabalho realizado, considera essa pesquisa associada a outros três filtros a serem aplicados em cada tema para a definição das prioridades. Isso sugere uma não paridade do processo participativo, pois a importância da Opinião Pública foi de apenas 30\% contra outros 70\% compostos pelo diagnóstico rápido dos indicadores e pelos outros filtros: ambiental, técnico e econômico. Após o diagnóstico pelos indicadores dos 23 temas e o levantamento e aplicação dos quatros filtros, tem-se a priorização dos temas para as estratégias do Plano de Ação. No Quadro 2 apresenta-se o comparativo de cada uma dessas avaliações e do resultado apresentado para os temas prioritários.

Foram definidas como áreas prioritárias: 1: Mobilidade/ Transporte, 2: Desigualdade Urbana/ Uso do Solo / Ordenamento Territorial, 3: Gestão Pública 
Moderna / Impostos e Autonomia Financeira, 4: Competitividade da Economia, 5: Segurança, 6: Energia e 7: Educação.

Quadro 2 - Comparação das avaliações das áreas prioritárias

\begin{tabular}{|c|c|c|c|c|c|c|c|}
\hline \multirow{3}{*}{ 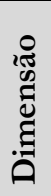 } & \multirow[b]{2}{*}{ Tema } & \multirow{2}{*}{$\begin{array}{c}\text { Avaliação } \\
\text { Indicadores }\end{array}$} & \multicolumn{4}{|c|}{ Filtros } & \multirow{3}{*}{ Priorização } \\
\hline & & & $\begin{array}{l}\text { Opinião } \\
\text { Pública }\end{array}$ & Ambiental & Técnico & Econômico & \\
\hline & Peso & $40 \%$ & $30 \%$ & $10 \%$ & $10 \%$ & $10 \%$ & \\
\hline \multirow{6}{*}{ 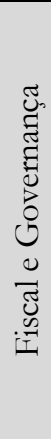 } & Dívida & Verde & Verde & - & Amarela & Amarela & Verde \\
\hline & $\begin{array}{l}\text { Gestão de gastos } \\
\text { públicos }\end{array}$ & Amarela & Verde & Amarela & Amarela & Vermelha & Amarela \\
\hline & $\begin{array}{l}\text { Impostos e } \\
\text { autonomia } \\
\text { financeira }\end{array}$ & Vermelha & Verde & - & Amarela & Vermelha & Vermelha \\
\hline & Transparência & Amarela & Verde & - & Amarela & & Amarela \\
\hline & $\begin{array}{l}\text { Gestão pública } \\
\text { moderna }\end{array}$ & Vermelha & Verde & - & Amarela & Vermelha & Vermelha \\
\hline & $\begin{array}{l}\text { Gestão pública } \\
\text { participativa }\end{array}$ & Amarela & Verde & - & Amarela & Verde & Amarela \\
\hline \multirow{8}{*}{ 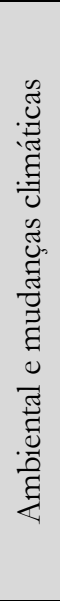 } & Água & Verde & Verde & Amarela & Amarela & Amarela & Verde \\
\hline & $\begin{array}{l}\text { Esgotamento } \\
\text { sanitário e } \\
\text { drenagem }\end{array}$ & Amarela & Verde & Amarela & Vermelha & Amarela & Amarela \\
\hline & $\begin{array}{l}\text { Gestão de } \\
\text { resíduos sólidos }\end{array}$ & Amarela & Verde & Amarela & Amarela & Vermelha & Amarela \\
\hline & Energia & Amarela & Verde & Vermelha & Amarela & Vermelha & Amarela \\
\hline & Qualidade do ar & Amarela & Verde & - & Verde & Verde & Amarela \\
\hline & $\begin{array}{l}\text { Mitigação de } \\
\text { mudanças } \\
\text { climáticas }\end{array}$ & Amarela & Verde & Vermelha & Verde & Verde & Amarela \\
\hline & Ruído & Amarela & Verde & - & Verde & Verde & Amarela \\
\hline & $\begin{array}{l}\text { Vulnerabilidade } \\
\text { diante de } \\
\text { desastres naturais }\end{array}$ & Amarela & Verde & Amarela & Verde & Verde & Amarela \\
\hline \multirow{9}{*}{ 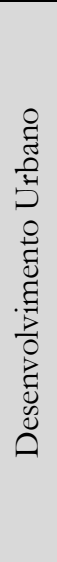 } & Saúde & Verde & Vermelha & Amarela & Amarela & Verde & Amarela \\
\hline & Segurança & Amarela & Vermelha & - & Amarela & Verde & Vermelha \\
\hline & Educação & Amarela & Amarela & Amarela & Amarela & Amarela & Amarela \\
\hline & Conectividade & Verde & Amarela & Amarela & Verde & Amarela & Verde \\
\hline & Emprego & Amarela & Amarela & - & Amarela & Vermelha & Amarela \\
\hline & $\begin{array}{l}\text { Competitividade } \\
\text { econômica }\end{array}$ & Vermelha & Verde & - & Amarela & Vermelha & Vermelha \\
\hline & $\begin{array}{l}\text { Mobilidade e } \\
\text { transporte }\end{array}$ & Vermelha & Amarela & Amarela & Vermelha & Amarela & Vermelha \\
\hline & $\begin{array}{l}\text { Desigualdade } \\
\text { urbana }\end{array}$ & Vermelha & Amarela & - & Vermelha & Amarela & Vermelha \\
\hline & $\begin{array}{l}\text { Uso do solo e } \\
\text { ordenamento } \\
\text { territorial }\end{array}$ & Amarela & Amarela & Vermelha & Vermelha & Amarela & Vermelha \\
\hline
\end{tabular}

Fonte: Palmas, 2015. Adaptado pelos autores.

Segundo o Plano, os temas educação e energia, mesmo com avaliação amarela na priorização, foram considerados estratégicos: o primeiro, "visando a melhoria de 
seus indicadores e sua importância para a melhoria da competitividade da cidade a médio e longo prazos" e, o segundo, "foi priorizado em função do elevado potencial para implantação de energia solar existente em Palmas e seu impacto positivo no desenvolvimento sustentável de Palmas" (PALMAS, 2015, p. 149).

É possível observar por meio do quadro comparativo que o peso de $40 \%$ da avaliação dos indicadores foi fundamental para o resultado final da priorização, considerando que somente os temas saúde e segurança apresentam avaliações diferentes entre os indicadores e a priorização. Saúde apareceu verde e segurança amarela segundo os indicadores, e ambos com avaliação vermelha no filtro Opinião Pública. O tema segurança foi o único em que a avaliação da Opinião Pública foi de fato relevante para a priorização.

Temas priorizados como energia e gestão pública moderna foram considerados em verde pela Pesquisa de Opinião Pública ${ }^{4}$ e vermelho pelos indicadores, fator que não alterou sua priorização. Isso demostra a fragilidade do processo participativo e da dimensão política da representação na tentativa de aumento da justiça social desse processo de planejamento urbano.

O tema relativo à mobilidade e transporte também merece atenção, pois o mesmo foi considerado vermelho pelos indicadores e pelo filtro Técnico. Desse modo, foi priorizado em primeiro lugar sem levar em conta que os filtros de Opinião Pública, Ambiental e Econômico o consideravam em avaliação amarela. A razão lógica dessa priorização não fica clara no texto do Plano, a não ser por aparente deliberação da prefeitura que, naquele momento, já realizava estudos para a implantação do BRT e precisava de apoio para a proposta.

Neste sentido, o peso da avaliação dos indicadores de $40 \%$ apoiado pelos $10 \%$ do filtro Ambiental, mais $10 \%$ do filtro Técnico e os outros $10 \%$ do filtro Econômico, todos elaborados por especialistas, sobrepujaram os $30 \%$ da Opinião Pública. Isso configura um aproveitamento incipiente do processo participativo na elaboração do diagnóstico do Plano de Ação Palmas Sustentável elaborado pelo programa ICES/BID, principalmente na possibilidade de permitir à sociedade construir os próprios parâmetros de desenvolvimento e qualidade de vida.

\section{Considerações finais}

Os estudos realizados neste artigo permitiram analisar a construção do diagnóstico do Plano de Ação Palmas Sustentável, publicado em 2015, na cidade de Palmas, capital do estado do Tocantins. Eles compreenderam os conceitos de

\footnotetext{
4 Temas priorizados como Competitividade Econômica e Impostos e Autonomia Financeira aparecem em verde, entretanto, não foram abordados no questionário da pesquisa.
} 
desenvolvimento em sua abordagem socioespacial urbana e da justiça social, todos trabalhados pela ICES/BID, principalmente durante a parte inicial do processo de planejamento que consistiu na escolha das cidades participantes do programa, na metodologia de elaboração do diagnóstico e na visão de cidade apresentada pelos indicadores e filtros para priorização dos temas.

Por meio da teoria discutida e das análises realizadas, foi possível observar que o conceito de desenvolvimento utilizado pelo Plano de Ação Palmas Sustentável não considera a justiça social como ponto de partida para seu processo de planejamento. A metodologia para elaboração do diagnóstico apresentado pela ICES, por meio dos critérios de escolha das cidades participantes, indicadores e filtros utilizados, não se mostra atenta de maneira efetiva a nenhuma das três dimensões da justiça social apresentada por Fraser (2008) (Quadro 3).

\section{Quadro 3 - Quadro síntese da análise quanto à justiça social}

\begin{tabular}{|l|l|l|}
\hline Ponto avaliado & Questão observada & Contradição \\
\hline $\begin{array}{l}\text { Justificativa de inclusão de } \\
\text { Palmas na ICES } \\
\text { IDH e renda per capita. }\end{array}$ & $\begin{array}{l}\text { Não consideração da desigualdade } \\
\text { urbana como ponto conflitante. }\end{array}$ & $\begin{array}{l}\text { Com a dimensão } \\
\text { redistributiva da justiça } \\
\text { social. }\end{array}$ \\
\hline $\begin{array}{l}\text { Metodologia do } \\
\text { diagnóstico e comparação } \\
\text { com diversas cidades. }\end{array}$ & $\begin{array}{l}\text { Não consideração das } \\
\text { características locais para definição } \\
\text { de critérios de qualidade de vida. }\end{array}$ & $\begin{array}{l}\text { Com a dimenão do } \\
\text { reconhecimento da justiça } \\
\text { social. }\end{array}$ \\
\hline $\begin{array}{l}\text { Metodologia de } \\
\text { priorização dos temas por } \\
\text { filtros, com peso de 30\% } \\
\text { para a pesquisa de opinião } \\
\text { pública. }\end{array}$ & $\begin{array}{l}\text { Não consideração paritária da } \\
\text { participação popular na priorização } \\
\text { dos temas. }\end{array}$ & $\begin{array}{l}\text { Com a dimensão da } \\
\text { representação da justiça } \\
\text { social. }\end{array}$ \\
\hline
\end{tabular}

Fonte: Elaborado pelos autores.

A dimensão redistributiva da justiça social é pouco considerada quando da confrontação entre a desigualdade urbana com o processo de desenvolvimento urbano da cidade, que demostra se importar mais com a renda per capita. A dimensão do reconhecimento da justiça social também não é utilizada como fundamento para reconhecer as peculiaridades históricas e culturais de cada sociedade no processo de construção dos próprios parâmetros de desenvolvimento e qualidade de vida. A dimensão da representação tampouco é utilizada em sua totalidade, visto que mesmo dispondo de algumas estratégias participativas, a paridade da participação não foi considerada. Desse modo, a Pesquisa de Opinião Pública não foi capaz de alterar significativamente os indicadores e, de fato, definir e priorizar os temas para ação na cidade.

A análise crítica do documento Plano de Ação Palmas Sustentável (2015), considerando Boisier (1996), sobretudo sobre o diagnóstico e a priorização dos temas para ação da gestão nos próximos anos, demonstra que o instrumento de 
planejamento urbano não foi concebido mediante o consenso político e pacto social para criar, coletivamente, um projeto de desenvolvimento. Ainda que, ao considerar de maneira tão frágil a participação popular, ignora a possibilidade de aumento da justiça social por meio da dimensão política da representação. Com isso, também impossibilita alcançar a melhoria da qualidade de vida da população e o real desenvolvimento socioespacial.

Nesse sentido, outros dois equívocos comuns quando se trata de desenvolvimento figuram no trabalho do programa ICES/BID, em Palmas. O primeiro se dá no fato de que o programa parece ainda trabalhar com a ideia do crescimento econômico como condição suficiente para o desenvolvimento, observando as desigualdades urbanas e sociais da cidade de Palmas de maneira dissociada de seu processo de desenvolvimento. O segundo ocorre ao apresentar o entendimento do conceito de desenvolvimento como um ponto específico a se alcançar, como numa escala na qual um território seria ou não desenvolvido ao apresentar algumas características pré-determinadas. Essa medida é apresentada como um padrão que pode ser aplicável a todas as realidades sociais, culturais e particularidades histórico-geográficas sem considerar as especificidades. Vale destacar que isso reflete um pensamento contrário às teorias de desenvolvimento apresentada neste artigo.

Como aspecto positivo, observa-se que o diagnóstico por indicadores e a fase de priorização de temas destacou alguns itens responsáveis pela busca por um desenvolvimento regional que pressupõe relações de dominação e dependência hierarquicamente ordenadas, privilegiando regiões de maior competitividade econômica.

Por fim, cabe considerar que a teoria discutida aponta para um modelo de planejamento e gestão urbanos em que o processo participativo permite aos habitantes conhecer a cidade, entender as forças que a controlam e incorporar os sujeitos ao processo político e ao seu controle (SOUZA, 2010). Dessa maneira, teria a possibilidade de incorporar todos os setores sociais, econômicos e políticos da população de forma a construir um pacto social, firmando compromisso entre cidadãos e governos na direção de um projeto de desenvolvimento.

O diagnóstico urbano deve ter metodologias e informações claras e acessíveis, possibilitando a discussão e a tomada de decisões conscientes e esclarecidas. Ele tem que ser capaz de formar um conjunto de regras simples para que toda a população as entenda, comprometa-se e sinta-se responsável por sua eficiência. As estratégias participativas devem buscar reconhecer o ponto de vista de diversos segmentos da sociedade de forma a confrontar o entendimento técnico dos temas e as informações sobre a cidade. Essa relação paritária entre a visão da sociedade e a dos técnicos deve ser a responsável pela identificação dos pontos de maior conflito para o município, caracterizados como temas principais para a reorganização territorial para a cidade. 


\section{REFERÊNCIAS}

BID. Guia metodológico Iniciativa Cidades Emergentes e Sustentáveis. Primeira edição. Bando Interamericano de Desenvolvimento. 2012.

BOISIER, S. Em Busca do Esquivo Desenvolvimento Regional: entre a caixapreta e o projeto político. Planejamento e Políticas Públicas, n. 13. Brasília: IPEA, 1996.

BOISIER, S. Post-scriptum sobre desenvolvimento regional: modelos reais e modelos mentais. Planejamento e Políticas Públicas, n. 19. Brasília: IPEA, 1999.

CORRÊEA, R. L. O espaço urbano. 3 ed. São Paulo: Ática, 1995.

EVANS, P. Além da "monocultura institucional": instituições, capacidades e desenvolvimento deliberativo. Revista Sociologias. Porto Alegre, ano 5, n. 9, p. 20-63, 2003. Disponível em: <https://dx.doi.org/10.1590/S151745222003000100003>. Acesso em: 16 mai 2016.

FRASER, N. Escalas de justicia. Barcelona: Herder Editorial, 2008.

G1 TO. Auditoria diz que BRT de Palmas é ilegal e está fora da realidade local. G1 TOCANTINS, Palmas, 22 mar. 2017. Disponível em: <http://g1.globo.com/to/tocantins/noticia/2017/03/auditoria-diz-que-brt-depalmas-e-ilegal-e-esta-fora-da-realidade-local.html>. Acesso em: 22 ago. 2017.

HEIDEMANN, F. G. Do sonho do progresso às políticas de desenvolvimento. In: HeIDEMANN, F. G.; SALM, J. F. (orgs.). Políticas Públicas e Desenvolvimento: bases epistemológicas e modelos de análise. Brasília: Editora da UnB, 2009.

MARICATO, E. et. al. Cidades rebeldes: Passe Livre e as manifestações que tomaram as ruas do Brasil. São Paulo: Boitempo: Carta Maior, 2013.

MARICATO, E. Para entender a crise urbana. São Paulo: Expressão Popular, 2015.

PALMAS. Plano de ação Palmas sustentável. Iniciativa Cidades Emergentes e Sustentáveis (ICES) Brasil, Banco Interamericano de Desenvolvimento (BID), Caixa Econômica Federal, Instituto Pólis, Prefeitura Municipal de Palmas - TO, 
2015. Disponível em: <http://polis.org.br/wp-content/uploads/PA-PalmasSustentavel_FINAL_low-1.pdf $>$. Acesso em: mai. 2016.

PIZZIO, A. Embates acerca da ideia de justiça social em relação a conflitos sociais e desigualdades. Revista de Administração Pública (RAP), v. 50, p. 355-375, 2016.

SOUZA, M. L. Mudar a cidade: uma introdução crítica ao planejamento e à gestão urbanos. 7 ed. Rio de Janeiro: Bertrand Brasil, 2010.

Endereço para correspondência:

Sarah Afonso Rodovalho - sarahrodovalho@uft.edu.br

Quadra 109 Norte, Avenida NS-15, ALCNO-14, Plano Diretor Norte

77.001-090 Palmas/TO, Brasil

AlexPizrio-alexpizzio@gmail.com

Quadra 109 Norte, Avenida NS-15, ALCNO-14, Plano Diretor Norte 77.001-090 Palmas/TO, Brasil

Monica Aparecida da Rocba Silva - monicars@uft.edu.br

Quadra 109 Norte, Avenida NS-15, ALCNO-14, Plano Diretor Norte 77.001-090 Palmas/TO, Brasil 